\title{
Low temperature matrix-isolation and solid state vibrational spectra of 5-chlorotetrazole $\dagger$
}

\author{
Susana C. S. Bugalho, ${ }^{a}$ A. C. Serra, ${ }^{b}$ Leszek Lapinski, ${ }^{a}$ M. Lurdes S. Cristiano ${ }^{c}$ and Rui Fausto*a \\ a Department of Chemistry (CQC), University of Coimbra, 3004-535 Coimbra, Portugal. \\ E-mail:rfausto@ci.uc.pt \\ ${ }^{b}$ Universidade Católica Portuguesa, Figueira da Foz, Portugal \\ ${ }^{c}$ Department of Chemistry, F.C.T. University of Algarve, 8000-117 Faro, Portugal
}

Received 11th December 2001, Accepted 24th January 2002

First published as an Advance Article on the web 15th April 2002

The vibrational spectra of 5-chlorotetrazole $\left(\mathrm{CN}_{4} \mathrm{HCl}\right)$ isolated in an argon matrix $(T=8.5 \mathrm{~K})$ and in the solid state (at room temperature) were studied. The infrared spectrum of monomers of 5-chlorotetrazole isolated in an argon matrix agrees well with the spectrum predicted theoretically (DFT(B3LYP)/6-31G*) for the $2 \mathrm{H}-$ tautomer of the compound. The bands assigned to the $1 \mathrm{H}$-tautomer appear in the experimental spectrum as very low intensity features. Based on the relative intensities of the bands in the spectra of the $1 \mathrm{H}-$ and $2 \mathrm{H}-$ tautomers, the relative amount of the first tautomer in this matrix can be estimated as $1 \%$. Three matrixes were deposited with different nozzle temperatures and the enthalpy difference between the tautomers $\Delta H=8.0 \mathrm{~kJ}$ $\mathrm{mol}^{-1}$ was estimated using the Van't Hoff relation. The internal energy difference between the two tautomers was predicted theoretically (DFT B3LYP/6-31G*) as $12.6 \mathrm{~kJ} \mathrm{~mol}^{-1}$. This is in reasonable agreement with experimental observations. In the crystalline phase, this compound exists in its $1 \mathrm{H}$-tautomeric form.

Accordingly, the IR spectrum of polycrystalline 5-chlorotetrazole is well reproduced by the spectrum predicted theoretically for the $1 \mathrm{H}$ - tautomer.

\section{Introduction}

Tetrazoles have drawn the attention of many people due to their important practical applications. The tetrazolic acid group, $-\mathrm{CN}_{4} \mathrm{H}$, has mostly been used as substitute for the carboxylic acid fragment, $-\mathrm{CO}_{2} \mathrm{H}$ because their $\mathrm{p} K_{\mathrm{a}}$ values are very similar. These groups are almost isosteric, but tetrazolic acid is metabolically more stable. ${ }^{1}$ Hence, replacement of $-\mathrm{CO}_{2} \mathrm{H}$ groups by $-\mathrm{CN}_{4} \mathrm{H}$ groups in biologically active molecules is widely applied in research areas of major interest. ${ }^{2}$ The earlier medicinal applications of tetrazoles have been reviewed. ${ }^{3-5}$ Indeed, the number of patent claims and publications related to tetrazoles used for medical purposes continues to grow rapidly. A wide range of tetrazole derivatives has been patented for antihypertension activity and as angiotensin II receptor antagonists. These are claimed to be useful for treating congestive heart failure and preventing cardiac hypertrophy. The tetrazole ring features in a range of antiallergic substances. A range of tetrazole derivatives has been explored for antituberculotic activity and compounds with the tetrazol1 -yl acetic acid structure have been claimed as aldose reductase inhibitors for treatment and prevention of diabetes complications. They are also currently used as anticonvulsants ${ }^{6}$ and in cancer and AIDS treatment. ${ }^{7,8}$ In addition, tetrazoles have found applications in agriculture, mainly as plant growth regulators, herbicides and fungicides. ${ }^{9}$ For example, $1 \mathrm{H}$-tetrazole has been added as a stabilizer to other active pesticides. Derivatives of tetrazoles are also added as stabilizers to silver halide photographic materials to prevent fogging during sto-

\footnotetext{
$\dagger$ Electronic supplementary information (ESI) available: Calculated molecular geometries, rotational constants, energies and dipole moments. Definition of internal symmetry coordinates used in the normal mode analysis. Experimental spectrum of polycrystalline 5-chlorotetrazole and calculated spectrum for the 1H-tautomer. See http:// www.rsc.org/suppdata/cp/b1/b111329c/
}

rage. ${ }^{10}$ An additional application of tetrazole compounds is as gas-generating agents for airbags. ${ }^{11}$

In the present study, 5-chlorotetrazole has been synthesised and studied by means of matrix-isolation infrared spectroscopy. This compound is important for the synthesis of tetrazolyl ethers. Due to the electron-withdrawing properties of the heteroaromatic tetrazole ring, tetrazolyl ethers are extensively used as intermediates for the conversion of phenols and allyl alcohols to the corresponding arenes and alkenes, through catalytic transfer reduction using hydrogen donors or cross-coupling using zinc or tin organometallics.

It has been reported that selective hydrogenolysis of the $\mathrm{C}-\mathrm{OH}$ bond in phenols ${ }^{12}$ and allyl alcohols ${ }^{13}$ could be conveniently achieved by first reacting the alcohol with 5-chloro1-phenyltetrazole so as to form the heteroaromatic aryl or allyl ether, which then undergoes smooth heterogeneously catalysed transfer hydrogenolysis to form the arene or alkene corresponding to the aryl or allyl group and water-soluble phenyltetrazolone. Selective transfer reduction of allyloxytetrazoles is remarkable because it competes with hydrogenation of the double bond ${ }^{13}$ and also with the relatively easy Claisen-type sigmatropic rearrangement. ${ }^{14}$ The heteroaromatic tetrazole, together with oxygen from the original alcohol or phenol, acts as an excellent leaving group in catalysed ipso-substitutions.

5-Chlorotetrazole is also a particularly interesting molecule because it exhibits tautomerism. Two tautomeric forms of the compound must be taken into account. They are presented in Fig. 1. Both $2 \mathrm{H}$ - and $1 \mathrm{H}$-tautomeric forms were previously observed $^{15}$ for matrix-isolated tetrazole itself.

\section{Experimental and computational methods}

5-Chlorotetrazole was prepared from commercial 5-aminotetrazole (Aldrich), which by diazotization in the presence of 


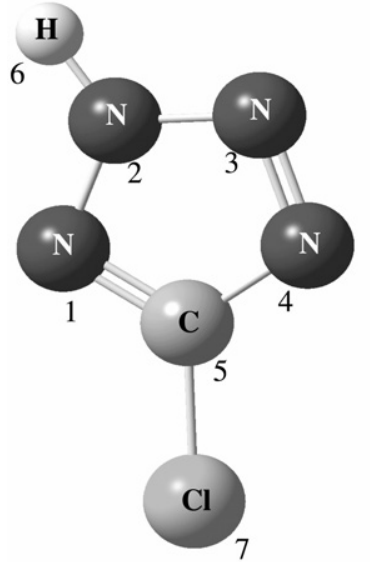

5-chloro-2H-tetrazole

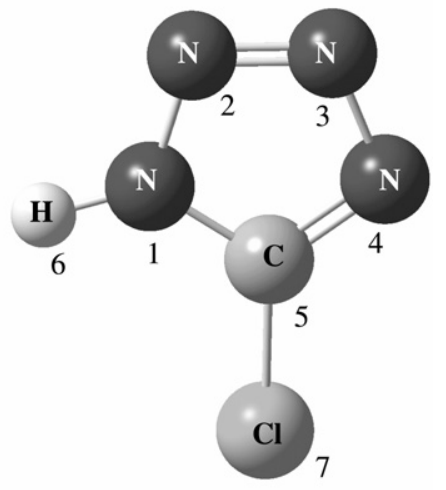

5-chloro-1H-tetrazole
Fig. 1 1H- and 2H- tautomers of 5-chlorotetrazole, with atom numbering.

hypophosphorous acid ${ }^{16}$ produces sodium 5-chlorotetrazole as a stable salt that can then be easily converted to 5-chlorotetrazole by acidification with $\mathrm{HCl}$. A sample of 5-chlorotetrazole was purified by vacuum sublimation prior to the matrixisolation experiments. The 5-chlorotetrazole obtained has $\mathrm{mp}=73^{\circ} \mathrm{C}\left(\mathrm{mp} 72-73^{\circ} \mathrm{C}\right)^{16}$ and elemental analysis compatible with the pure compound: calc.: C 11.49, H 0.96, N 53.62; found: C 11.57, H 0.91, N 53.77. The signal of a unique carbon atom in the molecule was observed in ${ }^{13} \mathrm{C}$ NMR spectroscopy at $153.22 \mathrm{ppm}$ (in $\mathrm{CDCl}_{3}$, with TMS as the internal standard). Mass spectrometry confirmed the calculated $104 \mathrm{u}$ mass of the compound: $m / z\left(\mathrm{CI} ; \mathrm{NH}_{3}\right) 105(\mathrm{M}+\mathrm{H})^{+} ; 122\left(\mathrm{M}+\mathrm{NH}_{4}\right)^{+}$.

Infrared spectra were obtained using a Mattson Infinity 60AR FT-spectrometer equipped with a DTGS detector and a $\mathrm{Ge} / \mathrm{KBr}$ beamsplitter. Data collection was performed with $0.5 \mathrm{~cm}^{-1}$ spectral resolution. All matrix-isolation experiments were done on the basis of an APD cryogenics closed-cycle helium refrigeration system with a DE-202A expander. A glass vacuum system and standard manometric procedures were used to deposit the matrix gas (argon, Air Liquid, 99.9999\%) using a deposition rate of $c a .10 \mathrm{mmol} \mathrm{h}^{-1}$. 5-Chlorotetrazole was co-deposited from a specially designed Knudsen cell with shut-off possibility which has two independent thermostattable parts, the valve nozzle and the sample compartment. ${ }^{17}$ For all matrixes, the temperature of the cold substrate CsI window was kept constant at $8.5 \mathrm{~K}$ during spectra recording. The solid state spectrum was obtained in a $\mathrm{KBr}$ pellet at room temperature.

Density functional theory calculations were carried out using the Becke-style 3-parameter functional with Lee-YangParr correlation part (B3LYP). ${ }^{18-20}$ The standard 6-31G* basis set was applied for these calculations. ${ }^{21}$ Molecular geometries were fully optimized, with tight convergence criteria, using the Berny gradient algorithm. ${ }^{22}$ Subsequently, harmonic vibrational frequencies and IR intensities were calculated at the optimized geometries corresponding to $1 \mathrm{H}-$ and $2 \mathrm{H}$ - forms of the compound. In order to correct for anharmonicity of the vibrations, the neglected part of electron correlation and basis set truncation, the calculated (B3LYP/6-31G*) wavenumbers were scaled down by a single scale factor $(0.9614){ }^{23}$ Normal coordinate analysis was undertaken using the programs TRANSFORMER, BUILD-G and VIBRAT, ${ }^{24}$ which are interfaced to GAUSSIAN 98. Optimized geometries of $1 \mathrm{H}$ - and $2 \mathrm{H}$ - tautomers are given in Table S1. $\dagger$ Internal coordinates used in the normal coordinate analysis are given in Table S2.†

\section{Results and discussion}

For isolated molecules of 5-chlorotetrazole, the theoretical calculations carried out at the DFT(B3LYP)/6-31G* level predict the $2 \mathrm{H}$-tautomer to be more stable than the $1 \mathrm{H}$-form. The predicted geometries for both tautomers closely follow the trends previously observed for unsubstituted tetrazole. ${ }^{15}$ In particular, a more extensive delocalisation within the tetrazole ring is predicted for 5 -chloro- $2 \mathrm{H}$-tetrazole than for 5 -chloro- $1 \mathrm{H}$ tetrazole. This is clearly shown by comparing the calculated values for the $\mathrm{N}-\mathrm{N}$ and for both $\mathrm{N}=\mathrm{N}$ and $\mathrm{C}=\mathrm{N}$ bonds that

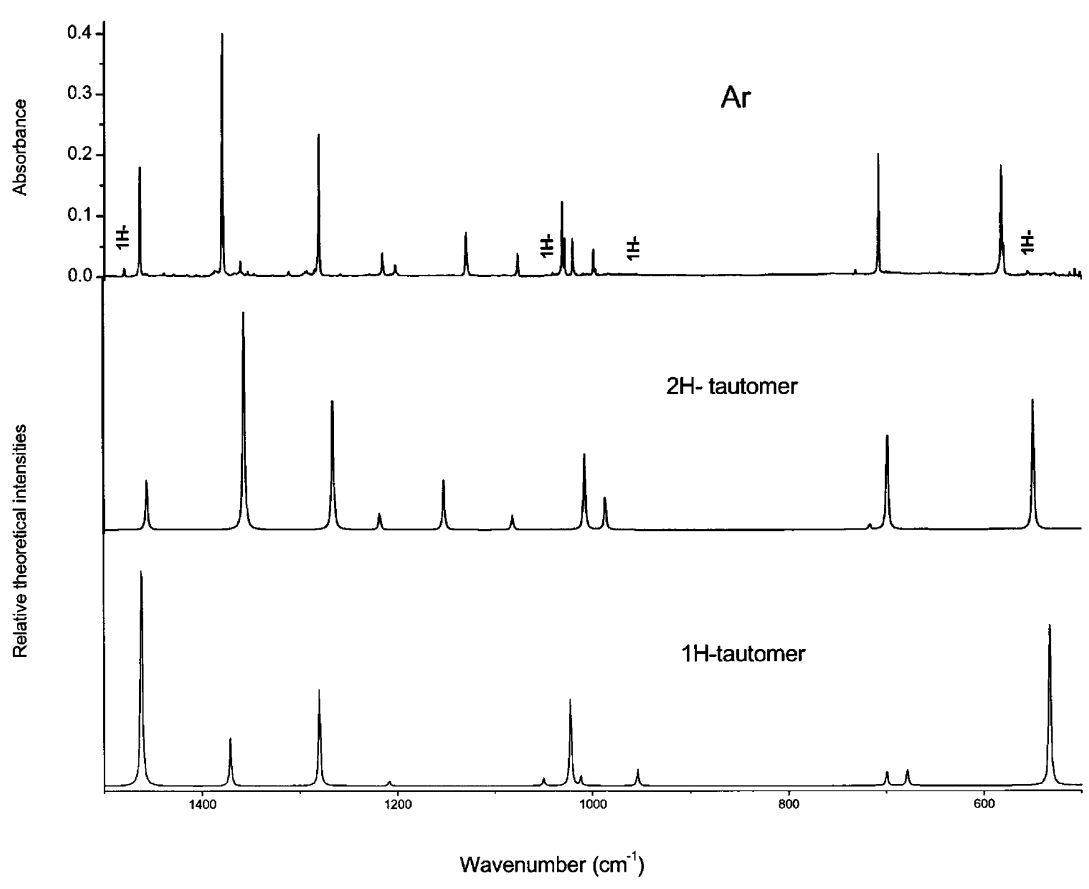

Fig. 2 Infrared spectra of 5-chlorotetrazole: Experimental spectrum of the compound isolated in Ar matrix; theoretical spectrum calculated for $2 \mathrm{H}$-tautomer and theoretical spectrum calculated for $1 \mathrm{H}$-tautomer; theoretical spectra calculated at DFT(B3LYP)/6-31G* level, theoretical frequencies scaled by a single factor 0.9614 . 


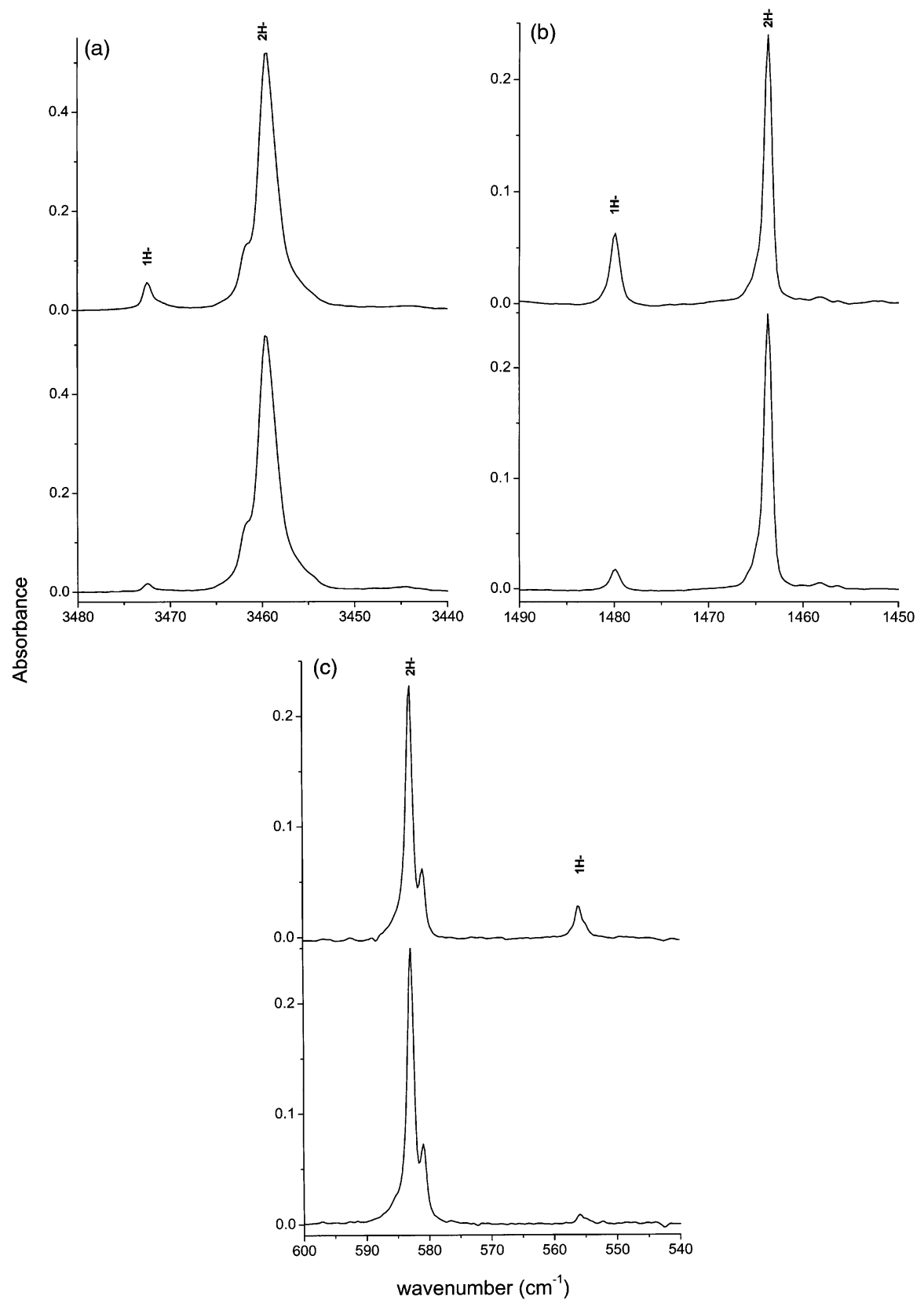

Fig. 3 Fragments of experimental spectra of 5-chlorotetrazole isolated in Ar matrixes: lower spectrum deposition with nozzle temperature $297 \mathrm{~K}$; upper spectrum with nozzle temperature $481 \mathrm{~K}$.

are respectively shorter and longer in the $2 \mathrm{H}$-tautomer than in the $1 \mathrm{H}$-form. The difference in electronic energies calculated at this level of theory is $14.19 \mathrm{~kJ} \mathrm{~mol}^{-1}$ and, after correction for zero point vibrational energy, this value is reduced to $12.6 \mathrm{~kJ}$ $\mathrm{mol}^{-1}$. Calculations with a larger basis set $\left(6-31++\mathrm{G}^{* *}\right)$ lead to a very similar energy difference, $13.1 \mathrm{~kJ} \mathrm{~mol}^{-1}$. For unsubstituted tetrazole $\left(\mathrm{CN}_{4} \mathrm{H}_{2}\right)$ analogous calculations also predict the $2 \mathrm{H}$ - form as the most stable tautomer, but the difference in energy between the two forms was only $9.96 \mathrm{~kJ} \mathrm{~mol}^{-1}$. The $2 \mathrm{H}$-tautomer was recently observed ${ }^{15}$ for that compound as a dominating form, but a minor contribution $(10 \%)$ of the $1 \mathrm{H}$-form was also found to be present in low-temperature inert matrixes. According to theoretical predictions, the relative amount of $1 \mathrm{H}$-tautomer in the case of 5-chlorotetrazole should be less than in the parent compound.

To the best of our knowledge, no studies have so far been devoted to the experimental investigation of tautomerism in 5-chlorotetrazole. Thus, we decided to study this compound

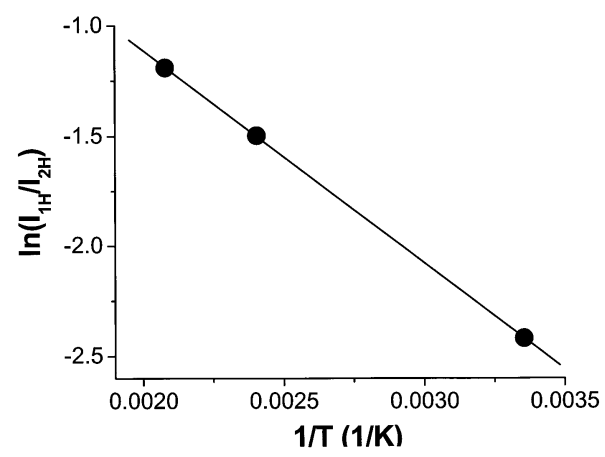

Fig. 4 Van't Hoff plot of the natural logarithm of the ratio of intensities of the bands at 1480.0 (1H-tautomer) and $1463.8 \mathrm{~cm}^{-1}(2 \mathrm{H}$-tautomer) as a function of reciprocal temperature of the nozzle. Values corresponding to three nozzle temperatures 297,416 and $481 \mathrm{~K}$ are presented. 


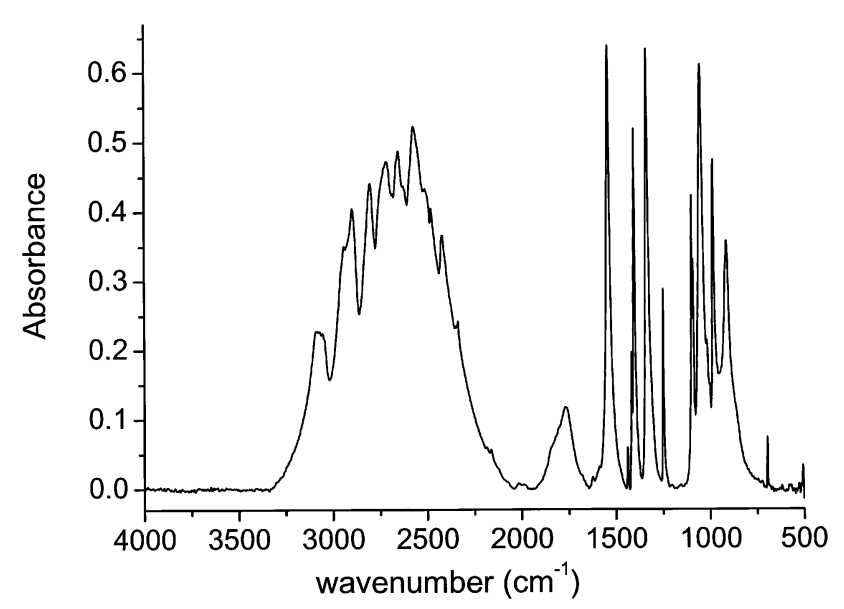

Fig. 5 Infrared spectrum of polycrystalline 5-chlorotetrazole in a $\mathrm{KBr}$ pellet (room temperature).

by matrix-isolation Fourier transform infrared spectroscopy, taking advantage of the unique features of this technique. The main strategy followed in the present study, relies on the fact that, in the majority of cases, matrix-isolation enables one to trap efficiently in the low temperature matrix the gasphase equilibrium existing in the sample vapour prior to deposition. $^{25-27}$ Then, taking advantage of the high spectral resolution typical of matrix-isolation spectroscopic experiments (usually, a few tenths of a $\mathrm{cm}^{-1}$ ), ideal conditions can be achieved to identify characteristic spectroscopic features due to the different species trapped in the matrix, and based on these it is possible to estimate the composition of the deposited gaseous mixture.

The experimental spectrum of 5-chlorotetrazole deposited into an argon matrix through a nozzle kept at room temperature is presented in Fig. 2. This spectrum is compared with the spectra theoretically calculated for $1 \mathrm{H}$ - and $2 \mathrm{H}$ - forms at DFT B3LYP/6-31G* level. The most prominent bands in the experimental spectrum are well reproduced by the DFT simulation carried out for the $2 \mathrm{H}$ - form, indicating that this species is the dominant tautomer in the gaseous phase.

Besides the sample of matrix-isolated 5-chlorotetrazole prepared with the compound-inlet-nozzle kept at room temperature, two other matrixes were deposited with the nozzle kept at elevated temperatures (416 and $481 \mathrm{~K}$ ). In the spectra of these matrixes the same bands were observed, as presented in Fig. 2, but relative intensities of a set of bands increased several times. These bands were of very low intensities (though visible) in the spectrum of the matrix prepared with the nozzle at room temperature, and they fit well to the strongest bands predicted for the $1 \mathrm{H}$ - form. The comparison of relative intensities of the bands due to $2 \mathrm{H}$ - and $1 \mathrm{H}$ - isomers of 5-chlorotetrazole observed for matrixes prepared at different nozzle temperatures is presented in Fig. 3, clearly showing a relative increase with temperature of the population of the higher energy form (1H-).

Assuming that what is observed in the low temperature matrixes is a frozen gas phase equilibrium, it is possible to estimate the enthalpy difference between the tautomers $\Delta H$. Taking into consideration our previous results for unsubstituted tetrazole, ${ }^{15}$ it is not expected that annealing of the matrixes up to a temperature where aggregation starts to occurs ( $c a$. $20 \mathrm{~K}$ ) could produce any spectral changes. The ratio of the integral intensities of the bands at 1463.8 and $1480.0 \mathrm{~cm}^{-1}$ has been measured for each of the three nozzle temperatures and the logarithm of it has been plotted (Fig. 4) as a function of the reciprocal temperature. This pair of bands has been chosen for the enthalpy estimation because the band at 1480.0 $\mathrm{cm}^{-1}$ is one of the strongest absorptions in the spectrum of the $1 \mathrm{H}$-tautomer, and this is a clear spectral region where the conditions of measurement are optimised.

The Van't Hoff plot fits very nicely $(R=0.99998)$ to a linear regression. From the slope of this regression the enthalpy difference between the tautomers was found to be $8.0 \mathrm{~kJ} \mathrm{~mol}^{-1}$. Similarly to what was observed for tetrazole itself ${ }^{15}$ the experimental value is lower than that resulting from theoretical calculations carried out at the DFT(B3LYP)/6-31G* level.

In 5-chlorotetrazole, as well as in unsubstituted tetrazole, there are 15 normal modes: 11 of $\mathrm{A}^{\prime}$ and 4 of $\mathrm{A}^{\prime \prime}$ symmetry. The experimentally observed absorption bands are compared with those theoretically predicted for both tautomeric forms in Table 1. The presence of the heavy chlorine atom attached directly to the tetrazole ring, in place of the hydrogen atom, changes the observed spectral pattern significantly. In fact, only the bands due to the stretching and wagging vibrations of the NH group were found in the spectrum of 5-chlorotetrazole close to the positions where they were previously ${ }^{15}$ observed for tetrazole. The frequencies of the $\nu \mathrm{NH}$ bands of 5-chlorotetrazole, 3472.5 (1H-form) and 3459.7 (2H-form), are lower than for tetrazole $\left(3484.3\right.$ and $3468.8 \mathrm{~cm}^{-1}$, respectively). The same situation occurs for the $\gamma \mathrm{NH}$ bands: they were observed at 556.2 (1H-form) and $583.1 \mathrm{~cm}^{-1}$ (2H-form), whereas for tetrazole ${ }^{15}$ the corresponding frequencies were higher, 573.4 and $592.1 \mathrm{~cm}^{-1}$. Another obvious consequence of substitution of the hydrogen atom in tetrazole by chlorine is the disappearance from the spectrum of the bands corresponding to the modes involving $\mathrm{C}-\mathrm{H}$ vibrations. The most noticeable is the disappearance of the band due to $\gamma \mathrm{CH}$ at $876.8 \mathrm{~cm}^{-1}$ (in the spectrum of $2 \mathrm{H}$-tetrazole). For 5-chlorotetrazole a large region free of any IR bands is observed in the frequency range $950-735 \mathrm{~cm}^{-1}$. Those vibrations involving a more substantial participation of the chlorine atom, $\nu(\mathrm{C}-\mathrm{Cl})$, $\beta(\mathrm{C}-\mathrm{Cl})$ and $\gamma(\mathrm{C}-\mathrm{Cl})$, were predicted to occur at low frequencies, below the limit of the experimentally studied region. We note that the theoretical spectra shown in Table 1 have been calculated for a 5-chlorotetrazole molecule bearing the ${ }^{35} \mathrm{Cl}$ isotope. However, the changes between these spectra and those calculated for the ${ }^{37} \mathrm{Cl}$ isotopomer were found to be only noticeable for those normal vibrations in which the chlorine atom is directly involved, that have predicted frequencies below $500 \mathrm{~cm}^{-1}$. For bands with frequencies higher than 500 $\mathrm{cm}^{-1}$, the positions of the bands in the spectra of two isotopomers should, according to the calculations, differ by no more than $1 \mathrm{~cm}^{-1}$.

The IR spectrum of polycrystalline 5-chlorotetrazole is shown in Fig. 5. Comparison of the calculated spectra of the two tautomers with this spectrum reveals that, as for unsubstituted tetrazole, ${ }^{15}$ 5-chlorotetrazole exists in the solid state exclusively in the more polar $1 \mathrm{H}$-tautomeric form (see also Fig. S1†). Taking as basis the theoretical data and the experimental information obtained for the isolated 5-chloro-1H-tetrazole, the assignment of the spectrum of the crystal could be done in a relatively straightforward way. Since, in the crystal, intermolecular interactions will involve mainly the $\mathrm{N}-\mathrm{H}$ fragment, ${ }^{15,28}$ it could be expected that those modes with predominant contributions from coordinates associated with this group should be more affected by intermolecular interactions, and deserve further comments here.

The $\nu(\mathrm{N}-\mathrm{H})$ stretching, $\delta(\mathrm{N}-\mathrm{H})$ in-plane bending and $\gamma(\mathrm{N}-$ $\mathrm{H})$ out-of-plane bending modes are expected to be those showing larger frequency shifts upon going from the monomeric species to the crystalline state. In the first case, a shift to lower frequencies is expected, due to the participation of the $\mathrm{N}-\mathrm{H}$ group in intermolecular H-bonding, while in the case of the bending modes shifts to higher frequencies are expected due both to H-bonding and the crystal packing forces. ${ }^{15}$ Accordingly, in the crystal spectrum $\nu(\mathrm{N}-\mathrm{H})$ appears as a broad com- 
Table 1 Calculated and observed vibrational frequencies, intensities and potential energy distributions (PED) for $2 \mathrm{H}$ and $1 \mathrm{H}-5$-chlorotetrazole ${ }^{a}$

\begin{tabular}{|c|c|c|c|c|c|c|c|}
\hline \multirow[b]{3}{*}{ Approximate description } & \multirow[b]{3}{*}{ Symmetry } & \multirow{2}{*}{\multicolumn{2}{|c|}{$\begin{array}{l}\text { Calculated } \\
\left(\mathrm{B} 3 \mathrm{LYP} / 6-31 \mathrm{G}^{*}\right)\end{array}$}} & \multicolumn{3}{|c|}{ Observed } & \multirow[b]{3}{*}{$\mathrm{PED}^{b}$} \\
\hline & & & & (Argon, & $.5 \mathrm{~K})$ & & \\
\hline & & $\nu$ (scaled) & $I^{\mathrm{ir}}$ & $\nu$ & $I^{\mathrm{ir}}$ & $\nu^{\text {ir }}$ & \\
\hline \multicolumn{8}{|l|}{ 5-Chloro-2H-tetrazole } \\
\hline$\nu(\mathrm{N}-\mathrm{H})$ & $\mathrm{A}^{\prime}$ & 3499.5 & 111.9 & 3459.7 & 167.0 & & $\nu(\mathrm{N}-\mathrm{H}) 100$ \\
\hline$\delta(\mathrm{N}-\mathrm{H})$ & $\mathrm{A}^{\prime}$ & 1455.9 & 21.8 & 1463.8 & 33.4 & & $\delta(\mathrm{N}-\mathrm{H}) 50, \nu(\mathrm{C}=\mathrm{N}) 27, \nu(\mathrm{N}=\mathrm{N}) 11$ \\
\hline$\nu(\mathrm{C}=\mathrm{N})$ & $\mathrm{A}^{\prime}$ & 1356.7 & 101.9 & 1379.7 & 79.6 & & $\nu(\mathrm{C}=\mathrm{N}) 46, \delta(\mathrm{N}-\mathrm{H}) 18, \delta($ ring 1$) 15, \nu(\mathrm{C}-\mathrm{Cl}) 13$ \\
\hline$\nu(\mathrm{C}-\mathrm{N})$ & $\mathrm{A}^{\prime}$ & 1265.6 & 64.9 & 1280.9 & 41.3 & & $\nu(\mathrm{C}-\mathrm{N}) 43, \nu(\mathrm{N}=\mathrm{N}) 28$ \\
\hline$\nu(\mathrm{N}=\mathrm{N})$ & $\mathrm{A}^{\prime}$ & 1217.6 & 8.1 & $\left\{\begin{array}{l}1216.0 \\
1203.1\end{array}\right.$ & $\begin{array}{l}6.9 \\
3.9\end{array}$ & & $\nu(\mathrm{N} 1-\mathrm{N} 2) 40, \nu(\mathrm{N}=\mathrm{N}) 38, \nu(\mathrm{C}-\mathrm{N}) 19$ \\
\hline$\nu(\mathrm{N} 1-\mathrm{N} 2)$ & $\mathrm{A}^{\prime}$ & 1152.2 & 22.5 & 1130.4 & 18.7 & & $\nu(\mathrm{N} 1-\mathrm{N} 2) 39, \delta($ ring2) $19, \nu(\mathrm{N}=\mathrm{N}) 19$ \\
\hline$\nu(\mathrm{N} 2-\mathrm{N} 3)$ & $\mathrm{A}^{\prime}$ & 1081.9 & 6.4 & $\begin{array}{r}1077.9 \\
1032.1\end{array}$ & $\begin{array}{l}8.8 \\
21.6\end{array}$ & & $\nu(\mathrm{N} 2-\mathrm{N} 3) 80, \delta$ (ring2) 15 \\
\hline$\delta$ ring FR with $2 \gamma(\mathrm{N}-\mathrm{H})$ & $\mathrm{A}^{\prime}$ & 1007.8 & 34.7 & $\begin{array}{l}1029.5 \\
1021.4\end{array}$ & $\begin{array}{l}8.8 \\
10.8\end{array}$ & & $\delta($ ring2) $55, \delta(\operatorname{ring} 1) 14, \nu(\mathrm{C}=\mathrm{N}) 11$ \\
\hline$\delta$ ring & $\mathrm{A}^{\prime}$ & 986.7 & 14.9 & $\left\{\begin{array}{r}1000.1 \\
998.2\end{array}\right.$ & $\begin{array}{l}5.7 \\
1.2\end{array}$ & & $\delta$ (ring1) $47, \nu(\mathrm{C}-\mathrm{N}) 25$ \\
\hline $\begin{array}{l}\tau \text { ring } \\
\tau \text { ring }\end{array}$ & $\begin{array}{l}\mathrm{A}^{\prime \prime} \\
\mathrm{A}^{\prime \prime}\end{array}$ & $\begin{array}{l}716.3 \\
698.4\end{array}$ & $\begin{array}{r}2.5 \\
48.1\end{array}$ & $\begin{array}{l}732.0 \\
708.3\end{array}$ & $\begin{array}{l}1.2 \\
36.4\end{array}$ & & $\begin{array}{l}\tau(\text { ring2) 48, } \tau \text { (ring1) } 37, \gamma(\mathrm{C}-\mathrm{Cl}) 11 \\
\tau(\text { ring1) } 50, \tau(\text { ring2) } 33, \gamma(\mathrm{N}-\mathrm{H}) 10\end{array}$ \\
\hline$\gamma(\mathrm{N}-\mathrm{H})$ & $\mathrm{A}^{\prime \prime}$ & 549.1 & 56.8 & $\left\{\begin{array}{l}583.1 \\
581.0\end{array}\right.$ & $\begin{array}{l}47.2 \\
7.9\end{array}$ & & $\gamma(\mathrm{N}-\mathrm{H}) 87, \tau($ ring 1$) 14$ \\
\hline$\nu(\mathrm{C}-\mathrm{Cl})$ & $\mathrm{A}^{\prime}$ & 492.4 & 1.6 & n.o. & & & $\nu(\mathrm{C}-\mathrm{Cl}) 72, \delta$ (ring 1$) 20$ \\
\hline$\delta(\mathrm{C}-\mathrm{Cl})$ & $\mathrm{A}^{\prime}$ & 319.1 & 2.6 & n.o. & & & $\delta(\mathrm{C}-\mathrm{Cl}) 93$ \\
\hline$\gamma(\mathrm{C}-\mathrm{Cl})$ & $\mathrm{A}^{\prime \prime}$ & 258.1 & 2.4 & n.o. & & & $\gamma(\mathrm{C}-\mathrm{Cl}) 81, \tau($ ring2) 19 \\
\hline $\begin{array}{l}\text { 5-Chloro-1H-tetrazole } \\
\nu(\mathrm{N}-\mathrm{H})\end{array}$ & $\mathrm{A}^{\prime}$ & 3507.4 & 98.0 & 3472.5 & 170.2 & $c$ & $\nu(\mathrm{N}-\mathrm{H}) 100$ \\
\hline$\delta(\mathrm{N}-\mathrm{H})$ & $\mathrm{A}^{\prime}$ & 1461.5 & 125.0 & 1480.0 & 170.2 & 1540 & $\delta(\mathrm{N}-\mathrm{H}) 36, \nu(\mathrm{C}=\mathrm{N}) 32, \nu(\mathrm{C}-\mathrm{N}) 13$ \\
\hline$\nu(\mathrm{C}=\mathrm{N}) ; \nu(\mathrm{C}-\mathrm{N})$ & $\mathrm{A}^{\prime}$ & 1371.1 & 23.0 & n.o. & & $\left\{\begin{array}{l}1439 \\
1415 \\
1403\end{array}\right.$ & $\nu(\mathrm{C}=\mathrm{N}) 42, \nu(\mathrm{C}-\mathrm{N}) 40$ \\
\hline$\nu(\mathrm{N}=\mathrm{N})$ & $\mathrm{A}^{\prime}$ & 1279.9 & 45.9 & n.o. & & 1336 & $\nu(\mathrm{N}=\mathrm{N}) 52, \nu(\mathrm{C}-\mathrm{N}) 12$ \\
\hline$\nu(\mathrm{N}=\mathrm{N}) ; \delta(\mathrm{N}-\mathrm{H})$ & $\mathrm{A}^{\prime}$ & 1208.4 & 2.4 & n.o. & & 1248 & $\nu(\mathrm{N}=\mathrm{N}) 38, \delta(\mathrm{N}-\mathrm{H}) 27, \nu(\mathrm{C}-\mathrm{N}) 11$ \\
\hline$\nu(\mathrm{N} 3-\mathrm{N} 4)$ & $\mathrm{A}^{\prime}$ & 1050.3 & 3.8 & n.o. & & $\left\{\begin{array}{l}1098 \\
1090\end{array}\right.$ & $\nu(\mathrm{N} 3-\mathrm{N} 4) 45, \delta($ ring 2$) 32, \nu(\mathrm{N} 1-\mathrm{N} 2) 19$ \\
\hline$\delta$ ring & $\mathrm{A}^{\prime}$ & 1022.6 & 45.5 & 1041.7 & 24.3 & $\left\{\begin{array}{l}1052 \\
1044\end{array}\right.$ & $\delta($ ring 1) $29, \delta($ ring 2) $23, \nu(\mathrm{N} 1-\mathrm{N} 2) 20, \delta(\mathrm{N}-\mathrm{H}) 13$ \\
\hline$\nu(\mathrm{N} 1-\mathrm{N} 2)$ & $\mathrm{A}^{\prime}$ & 1012.1 & 4.3 & n.o. & & $\left\{\begin{array}{l}1018 \\
1003\end{array}\right.$ & $\nu(\mathrm{N} 1-\mathrm{N} 2) 45, \delta$ (ring 1$) 28$ \\
\hline$\delta$ ring; $\nu(\mathrm{N} 3-\mathrm{N} 4)$ & $\mathrm{A}^{\prime}$ & 954.1 & 7.9 & 956.8 & 14.6 & $\left\{\begin{array}{l}985 \\
961\end{array}\right.$ & $\nu(\mathrm{N} 3-\mathrm{N} 4) 39, \delta($ ring 2$) 33, \delta($ ring 1$) 16, \nu(\mathrm{C}-\mathrm{N}) 10$ \\
\hline$\tau$ ring & $\mathrm{A}^{\prime \prime}$ & 699.4 & 7.7 & n.o. & & 723 & $\tau($ ring 1) 97 \\
\hline$\tau$ ring & $\mathrm{A}^{\prime \prime}$ & 678.4 & 8.4 & n.o. & & 697 & $\tau($ ring 2$) 81, \gamma(\mathrm{C}-\mathrm{Cl}) 15$ \\
\hline$\gamma(\mathrm{N}-\mathrm{H})$ & $\mathrm{A}^{\prime \prime}$ & 532.5 & 94.2 & 556.2 & 97.3 & $\left\{\begin{array}{l}915 \\
865\end{array}\right.$ & $\gamma(\mathrm{N}-\mathrm{H}) 95$ \\
\hline$\nu(\mathrm{C}-\mathrm{Cl})$ & $\mathrm{A}^{\prime}$ & 486.6 & 2.6 & n.o. & & n.o. & $\nu(\mathrm{C}-\mathrm{Cl}) 70, \delta$ (ring 1$) 20$ \\
\hline$\delta(\mathrm{C}-\mathrm{Cl})$ & $\mathrm{A}^{\prime}$ & 300.2 & 4.6 & n.o. & & n.o. & $\delta(\mathrm{C}-\mathrm{Cl}) 92$ \\
\hline$\gamma(\mathrm{C}-\mathrm{Cl})$ & $\mathrm{A}^{\prime \prime}$ & 246.4 & 3.3 & n.o. & & n.o. & $\gamma(\mathrm{C}-\mathrm{Cl}) 79, \tau($ ring 2$) 22$ \\
\hline
\end{tabular}

${ }^{a}$ Frequencies in $\mathrm{cm}^{-1} . \nu$, stretching, $\delta$, in-plane bending; $\gamma$, out-of-plane bending; $\tau$, torsion; FR, Fermi Resonance; n.o., not observed. See Fig. 1 for atom numbering. Calculated infrared intensities $\left(I^{\mathrm{ir}}\right)$ in $\mathrm{km} \mathrm{mol}^{-1}$. Experimental intensities are integrated intensities, scaled to the total calculated intensities of bands that have an experimental counterpart. ${ }^{b}$ Only PED contributions larger than $10 \%$ are presented. ${ }^{c}$ Very broad and complex band (see Fig. 5 and discussion in the text).

plex set of intense bands observed from $c a .3500 \mathrm{~cm}^{-1}$ to $c a$. $2300 \mathrm{~cm}^{-1}$. The observed pattern is similar to that found for unsubstituted tetrazole ${ }^{15}$ and is typical of $\nu(\mathrm{N}-\mathrm{H})$ vibrations participating in strong $\mathrm{H}$-bond interactions and being involved in multiple Fermi resonance interactions with overtones and combination tones of lower frequency fundamental vibrations. $^{29}$

The assignment of the $\delta(\mathrm{N}-\mathrm{H})$ in-plane bending was also made easily, since it is expected to appear in a clear spectral region above the frequency at which the corresponding band in the matrix-isolated spectrum of the $1 \mathrm{H}$-tautomer appears $\left(1480 \mathrm{~cm}^{-1}\right.$; see Table 1). So, $\delta(\mathrm{N}-\mathrm{H})$ in-plane bending must be assigned to the band at $1540 \mathrm{~cm}^{-1}$, in the spectrum of the crystal.
The $\gamma(\mathrm{N}-\mathrm{H})$ out-of-plane bending was expected to be strongly shifted to higher frequencies in the crystalline state, taking as reference the frequency of this mode observed in the matrix-isolated spectrum. For tetrazole itself, the observed shift in this vibration on going from the isolated monomer to the crystalline state is as large as $311 \mathrm{~cm}^{-1} \cdot{ }^{15}$ Being directly affected by intermolecular interactions, this mode could be expected to give rise to relatively broad bands. Fig. 6 shows the results of band deconvolution analysis of the spectroscopic profile within the $1160-760 \mathrm{~cm}^{-1}$ spectral region. This procedure clearly reveals that within this spectral range there are 10 bands contributing to the observed spectral profile. These correspond to 5 pairs of bands, ascribable to the $\nu(\mathrm{N} 3-\mathrm{N} 4)$ $\left(1098 / 1090 \mathrm{~cm}^{-1}\right)$ and $\nu(\mathrm{N} 1-\mathrm{N} 2)\left(1018 / 1003 \mathrm{~cm}^{-1}\right)$ stretching 


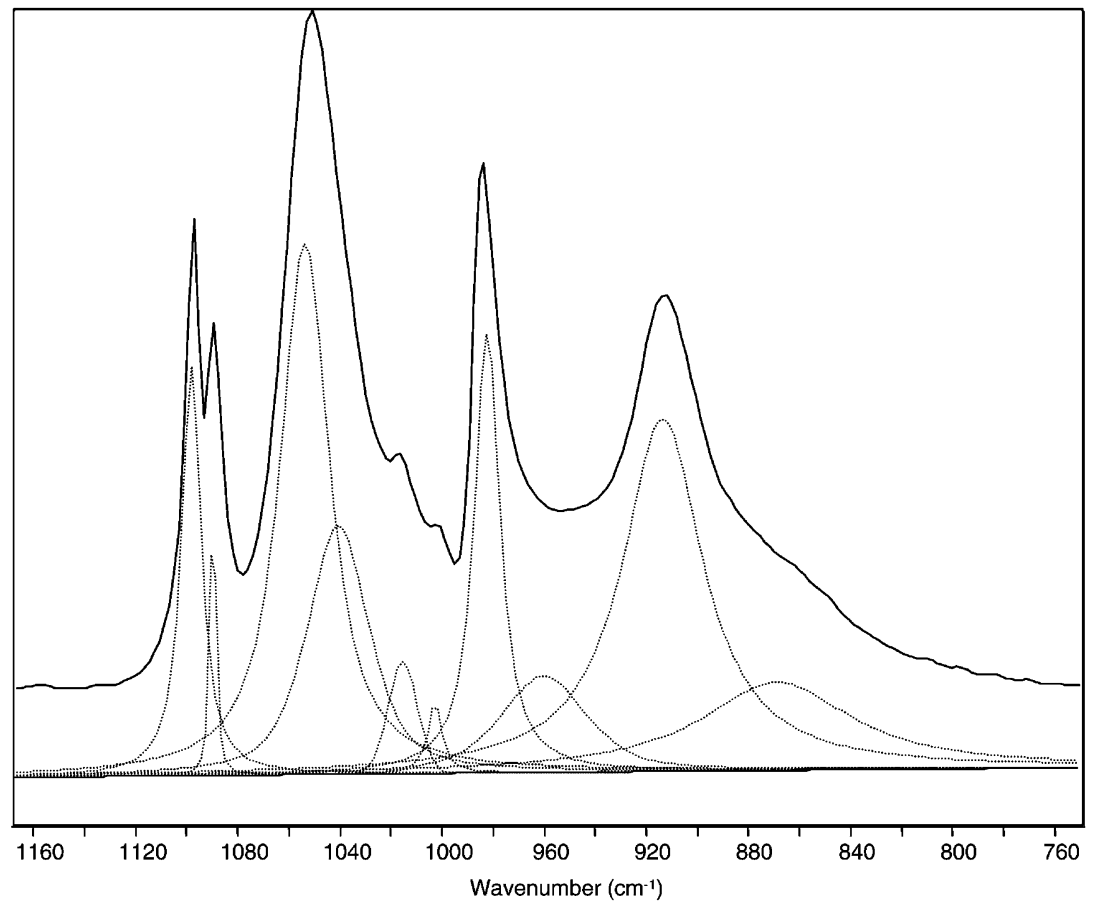

Fig. 6 Results from band-fitting analysis for the $1160-760 \mathrm{~cm}^{-1}$ region of the room temperature infrared spectrum of crystalline 5-chlorotetrazole. In the simulation, the Grams/32 AI 6.0 (Galactic Industries, Salem, NH, USA, 2000) software was used with Gaussian-Lorentzian type functions selected as adjusting functions.

vibrations, not observed in the matrix spectrum but predicted at 1050.3 and $1012.1 \mathrm{~cm}^{-1}$, respectively, to the two in-plane ring deformations $\left(1052 / 1044\right.$ and $985 / 961 \mathrm{~cm}^{-1}$; observed values for the matrix-isolated species: 1041.7 and 956.8 $\left.\mathrm{cm}^{-1}\right)$ and to the $\gamma(\mathrm{N}-\mathrm{H})$ out-of-plane bending $(915 / 865$ $\left.\mathrm{cm}^{-1}\right)$. The pair of bands assigned to $\gamma(\mathrm{N}-\mathrm{H})$ correspond to broad intense features which are shifted relatively to the band observed for 5-chloro-1H-tetrazole in argon by 358.8 and $308.8 \mathrm{~cm}^{-1}$, a shift similar to that previously observed for unsubstituted tetrazole ${ }^{15}\left(311 \mathrm{~cm}^{-1}\right)$. The shift of the same order of magnitude was observed ${ }^{30}$ for the $\tau(\mathrm{O}-\mathrm{H})$ torsional vibration in methyl glycolate $\left(\mathrm{CH}_{2} \mathrm{OHCOOCH}_{3}\right)$, where the position of the corresponding band changed on going from the matrix-isolated monomeric species $\left(303 \mathrm{~cm}^{-1}\right)$ to the crystalline state $\left(652,570 \mathrm{~cm}^{-1}\right)$.

\section{Conclusion}

Matrix-isolation and solid-state infrared spectroscopic measurements were carried out on 5-chlorotetrazole. The experimental studies were supported by theoretical predictions undertaken at the B3LYP/6-31G* level of theory. The $2 \mathrm{H}$-tautomer of the compound was predicted by the calculations to be the lowest energy tautomer and, in consonance with this result, it was experimentally observed as the dominating form in the matrix-isolation experiments. The minor $1 \mathrm{H}$-tautomer was populated more significantly only in experiments with elevated nozzle temperature. Estimation of the enthalpy difference between the tautomers led to the value of $8.0 \mathrm{~kJ} \mathrm{~mol}^{-1}$.

A detailed assignment of the observed infrared spectra of matrix-isolated monomeric 5-chlorotetrazole (both $1 \mathrm{H}$ - and $2 \mathrm{H}$-tautomers) was carried out, based on the results of the theoretically calculated spectra. The spectra recorded for polycrystalline 5-chlorotetrazole indicate that this compound, as unsubstituted tetrazole, ${ }^{15,28}$ exists as the more polar $1 \mathrm{H}$-tautomer in the crystalline state.

\section{Acknowledgement}

The authors acknowledge the Portuguese Science Foundation (FCT) for financial support (Research project PRAXIS/P/ QUI/10137/1998).

\section{References}

1 H. Singh, A. S. Chawla, V. K. Kapoor, D. Paul and R. K. Malhotra, Prog. Med. Chem., 1980, 17, 151

2 K. Noda, Y. Saad, A. Kinoshita, T. P. Boyle, R. M. Graham, A Husain and S. S. Karnik, J. Biol. Chem., 1995, 270, 2284.

3 T. Mavromoustakos, A. Kolocouris, M. Zervou, P. Roumelioti, J. Matsoukas and R. Weisemann, J. Med. Chem., 1999, 42, 1714.

4 J. H. Toney, P. M. D. Fitzgerald, N. Groversharma, S. H. Olson, W. J. May, J. G. Sundelof, D. E. Vanderwall, K. A. Cleary, S. K. Grant, J. K. Wu, J. W. Kozarich, D. L. Pompliano and G. G. Hammond, Chem. Biol., 1998, 5, 185.

5 Y. Hashimoto, R. Ohashi, Y. Kurosawa, K. Minami, H. Kaji, K. Hayashida, H. Narita and S. Murata, J. Cardiovasc. Pharm., $1998,31,568$.

6 A. Desarro, D. Ammendola, M. Zappala, S. Grasso and G. B. Desarro, Antimicrob. Agents Chemother., 1995, 39, 232.

7 Y. Tamura, F. Watanabe, T. Nakatani, K. Yasui, M. Fuji, T. Komurasaki, H. Tsuzuki, R. Maekawa, T. Yoshioka, K. Kawada, K. Sugita and M. Ohtani, J. Med. Chem., 1998, 41, 640.

8 A. D. Abell and G. J. Foulds, J. Chem. Soc., Perkin Trans. 1, 1997, 2475.

9 G. Sandmann, C. Schneider and P. Boger, Z. Naturforsch. C, 1996, 51, 534.

10 G. I. Koldobskii, V. A. Ostrovskii and V. S. Poplavskii, Khim. Geterotsikl. Soedin., 1981, 10, 1299.

11 C. Zhao-Xu and X. Heming, Int. J. Quantum Chem., 2000, 79, 350 . 
12 R. A. W. Johnstone and P. J. Price, Tetrahedron, 1985, 41, 2483.

13 M. L. S. Cristiano, R. A. W. Johnstone and P. J. Price, J. Chem. Soc., Perkin Trans. 1, 1996, 1453.

14 (a) M. L. S. Cristiano and R. A. W. Johnstone, J. Chem. Soc., Perkin Trans. 2, 1997, 489; (b) M. L. S. Cristiano and R. A. W. Johnstone, J. Chem. Res., 1997, 164.

15 S. C. S. Bugalho, E. M. S. Maçôas, M. L. S. Cristiano and R. Fausto, Phys. Chem. Chem. Phys., 2001, 3, 3541-3547.

16 R. Stolle, Ber. Dtsch. Chem. Ges. B, 1929, 62, 1118.

17 I. D. Reva, S. Stepanian, L. Adamowicz and R. Fausto, J. Phys. Chem. A, 2001, 105, 4773.

18 A. D. Becke, Phys. Rev. B, 1988, 38, 3098.

19 C. Lee, W. Yang and R. G. Parr, Phys. Rev. B, 1988, 37, 785.

20 S. H. Vosko, L. Wilk and M. Nusair, Can. J. Phys., 1980, 58, 1200 .

21 W. J. Hehre, R. Ditchefield and J. A. Pople, J. Chem. Phys., 1972, 56, 2257.

22 C. Peng, P. Y. Ayala, H. B. Schlegel and M. J. Frisch, J. Comput. Chem., 1996, 17, 49.

23 D. J. Defrees and A. D. McLean, J. Chem. Phys., 1985, 82, 333.
24 M. D. G. Faria and R. Fausto, TRANSFORMER, BUILD-G and VIBRAT (version 2.0), Department of Chemistry, University of Coimbra, Portugal, 1997. These programs incorporate several routines from programs GMAT and FPERT, H. Fuher, V. B. Kartha, P. J. Krueger and H. H. Mantsch, Natl. Res. Council Can. Bull., 1976, 15, 1

25 S. G. Stepanian, I. D. Reva, E. D. Radchenko, M. T. S. Rosado, M. L. T. S. Duarte, R. Fausto and L. Adamowicz, J. Phys. Chem. A, 1998, 102, 1041.

26 E. M. S. Maçôas, R. Fausto, J. Lundell, M. Pettersson, L. Khriachtchev and M. Räsänen, J. Phys. Chem. A, 2000, 104, 11725.

27 E. M. S. Maçôas, R. Fausto, M. Pettersson, L. Khriachtchev and M. Räsänen, J. Phys. Chem. A, 2000, 104, 6956.

28 R. Goddard, O. Heinemann and C. Krüger, Acta Crystallogr., Sect. C, 1997, 53, 590.

29 M. T. S. Rosado, M. L. T. S. Duarte and R. Fausto, J. Mol. Struct., 1997, 410-411, 343.

30 S. Jarmelo, T. M. R. Maria, M. L. P. Leitão and R. Fausto, Phys. Chem. Chem. Phys., 2000, 2, 1155. 